\title{
The determination of mercury content in the biomass untended for industrial power plant
}

\author{
Magdalena Wiktor ${ }^{1}$, Iwona Jelonek ${ }^{1}$, Marta Kasprzyk ${ }^{1, *}$, and Anna Szpak ${ }^{1}$ \\ ${ }^{1}$ University of Silesia, Faculty Earth of Sciences, 41-200 Sosnowiec, Będzińska 60 str., Poland
}

\begin{abstract}
Biomass is one of the oldest and most widely used renewable energy sources. The biomass is the whole organic matter of vegetable or animal origin which is biodegradable. Biomass includes leftovers from agricultural production, forestry residues, and industrial and municipal waste. The use of biomass in the power industry has become a standard and takes place in Poland and other European countries. This paper discusses the correlation of mercury content in different biomass types used in the power industry and in products of biomass combustion. Different biomass types, which are currently burned in a commercial power plant in Poland, were discussed. A photographic documentation of different biomass types, such as straw briquettes, wood briquettes, pellets from energy crops (sunflower husk and wood husk), wood pellets, wood chips, and agro-biomass (seeds) was carried out. The presented paper discusses the results obtained for 15 biomass samples. Five selected biomass samples were burned in controlled conditions in the laboratory at the University of Silesia. The ash resulting from the combustion of five biomass samples was tested for mercury content. A total of twenty biomass samples and its combustion products were tested. Based on the obtained results, it was found that any supply of biomass, regardless of its type, is characterized by variable mercury content in dry matter. In the case of e.g. wood chips, the spread of results reaches $235.1 \mu \mathrm{m} / \mathrm{kg}$ (in dry matter). Meanwhile, the highest mercury content, $472.4 \mu \mathrm{m} / \mathrm{kg}$ (in dry matter) was recorded in the biomass of straw, wood pellets, and pellets from energy crops (sunflower husk). In the case of combustion products of five selected biomass types, a three or four fold increase in the mercury content has been observed.
\end{abstract}

\section{Introduction}

Solid biomass, fired or co-fired with fossil fuels, is used in the Polish power sector for many years. According to the European Union and the guidelines of the Central Statistical Office of Poland, biomass is a biodegradable fraction of products, waste and residues (including substances of plant and animal origin), from agriculture, forestry and related industries, as well as a biodegradable fraction of municipal and industrial waste [1,2]. Solid biomass, included among renewable energy sources (RES), is an alternative to nonrenewable fossil fuels, e.g. coal. The demand for biomass from the EU and Polish power

\footnotetext{
*Corresponding author: marta.kasprzyk@,us.edu.pl
} 
industry is constantly increasing. Overall, the EU Member States produce electricity from the following renewable energy sources (Fig. 1).

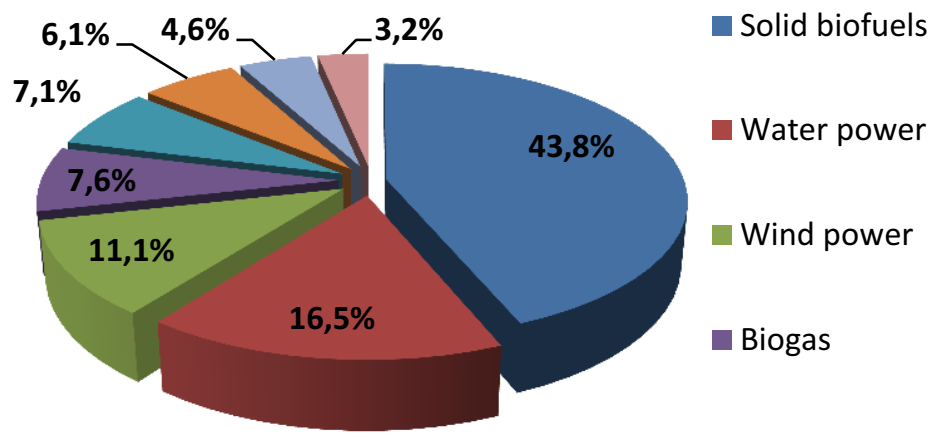

Fig. 1. Energy production from renewable sources in the EU broken down by media in 2014 [2].

However, the electricity generation in Poland is still based on fossil fuels, including bituminous coal and lignite, which occupy the first place with $56 \%$ share. Crude oil with the second-largest share is followed by natural gas (13\% share). Biomass and waste have the lowest (6\%) share in the energy production in Poland (Fig. 2).

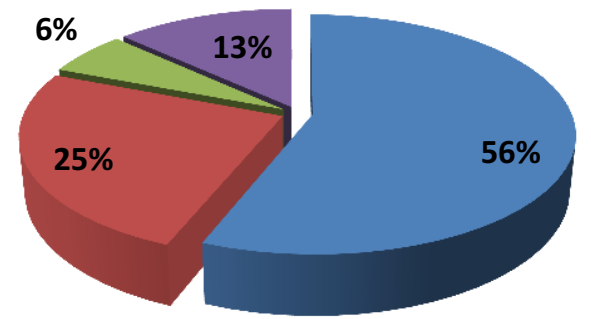

Coal

Crude oil

Biomass and waste

Natural gas

Fig. 2. The demand for primary energy by source [3].

The Polish government forecasts that the energy consumption in Poland in the years 2010-2020 will continue to increase at an average rate of $1.5 \%$ per year. The use of renewable energy between 2010 and 2020 should reach $12 \%$ [4].

While biomass is regarded as an alternative fuel for industrial power, its mercury content is the reason for increased $\mathrm{Hg}$ emissions into the environment resulting from biomass combustion. The level of mercury emissions depends on its content in the combusted fuel and the type of gas treatment system [5].

\section{Samples and analytical procedures}

The analyzed biomass samples were collected at one of commercial power plants. The samples were collected (according to the PN-90 / G04502 standard) and their qualitative characteristics were assessed. The research material was collected by the power plant employees and stored in sealed glass jars in an amount of 1 to $2 \mathrm{~kg}$ (each sample). A total of 15 samples of all types of biomass, burned in the power plant in the period from April to 
November 2015, were collected. The samples were transported to the laboratory, where a detailed description, along with photographic documentation presented in Table 1, was made.

In order to prepare samples for further analysis, the examined biomass samples were grinded and then pulverized in agate mortar. Each sample was divided into two equal portions, one of which was used for the $\mathrm{pH}$ and conductivity measurement, and the other of which was used for the mercury content measurement.

The electrical conductivity and $\mathrm{pH}$ measurements were carried out on approximately $40 \mathrm{~g}$ of each sample. The samples were placed in beakers, filled with distilled water to a volume of $100 \mathrm{ml}$. This solution was allowed to stand for $24 \mathrm{~h}$.

The measurement of total mercury content in the analyzed samples of solid biomass was performed using a DMA-80 (Milestone). Calibration of the analyzer was based on patterns provided by the manufacturer (NIST SRM). The analyzes were performed at the Laboratory of Water Analysis, Department of Earth Sciences, the University of Silesia. Five biomass samples were fired in a muffle furnace, and the resulting ash was further analyzed for total mercury using the same measurement technique as in the case of solid biomass samples.

\section{Results and discussion}

Macroscopic description of the samples and photographic documentation are summarized in Table 1. The mercury content, analytical moisture, $\mathrm{pH}$, and conductivity of biomass (Table 1) and ash resulting from biomass combustion are shown in Table 2.

Table 1. The mercury content, analytical moisture, $\mathrm{pH}$, and conductivity of the biomass.

\begin{tabular}{|c|c|c|c|c|c|c|c|}
\hline $\begin{array}{c}\text { No } \\
\text { sample }\end{array}$ & $\begin{array}{l}\text { Macroscopic } \\
\text { description }\end{array}$ & Raw samples & $\begin{array}{c}\text { Grinded and } \\
\text { averaged samples }\end{array}$ & $\begin{array}{c}\mathrm{Mad} \\
\%\end{array}$ & $\mathrm{PH}$ & Conductivity & $\begin{array}{c}\mathrm{Hg} \\
\mu / \mathrm{kg}\end{array}$ \\
\hline B1 & $\begin{array}{c}\text { Biomass } \\
\text { - straw } \\
\text { briauettes }\end{array}$ & & & 5.38 & 6.31 & 52.3 & 130.4 \\
\hline B2 & $\begin{array}{l}\text { Biomass } \\
\text { - wood }\end{array}$ & & & 6.43 & 5.91 & 67.4 & 295.0 \\
\hline B3 & $\begin{array}{c}\text { Biomass } \\
\text { - (Agro- } \\
\text { seeds) }\end{array}$ & & & 5.30 & 5.10 & 119.5 & 135.6 \\
\hline
\end{tabular}




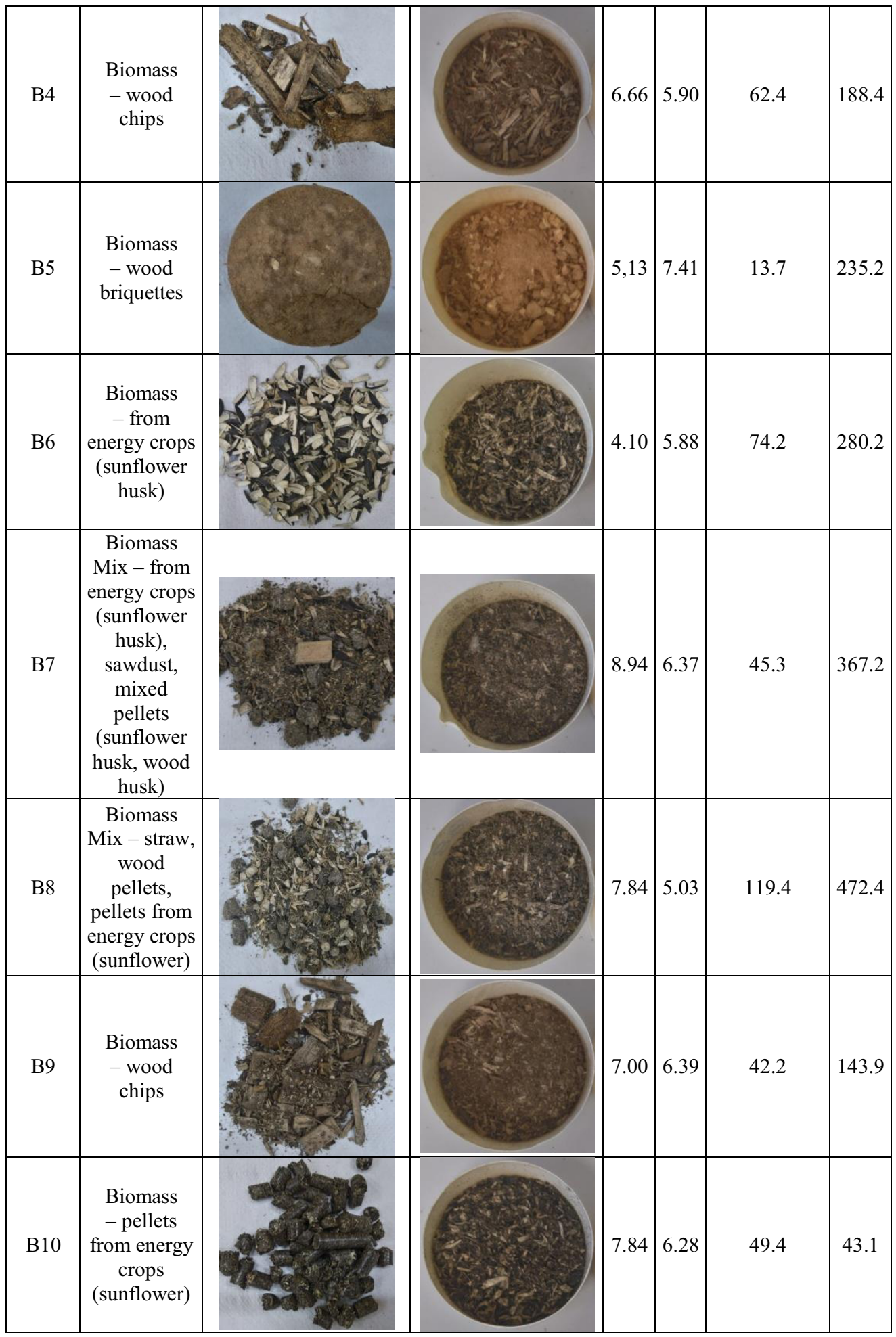




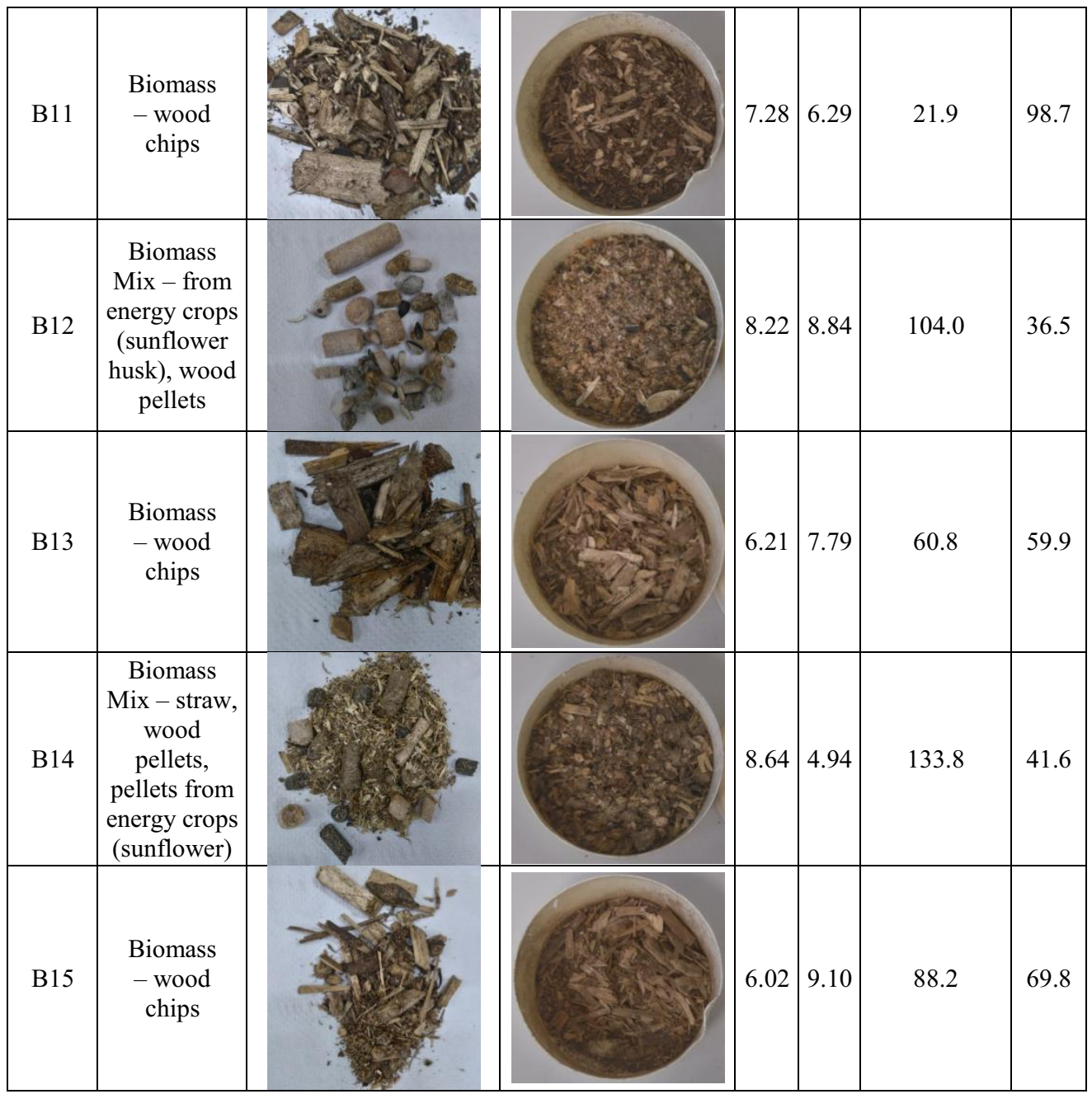

Mad - Analytical moisture

Table 2. The mercury content in ashes from biomass combustion.

\begin{tabular}{|c|c|c|}
\hline $\begin{array}{c}\text { No } \\
\text { sample }\end{array}$ & Macroscopic description & $\begin{array}{c}\mathrm{Hg} \\
\mu \mathrm{g} / \mathrm{kg}\end{array}$ \\
\hline B1-S & Biomass - straw briquettes & 297.3 \\
\hline B2-S & Biomass - wood chips & 177.5 \\
\hline B3-S & Biomass - Agro-seeds & 346.9 \\
\hline B4-S & Biomass - wood chips & 298.3 \\
\hline B5-S & Biomass - wood briquettes & 339.1 \\
\hline
\end{tabular}


A summary of mercury content in individual biomass types indicates that the mercury content in raw samples of straw briquettes amounts to $130.4 \mu \mathrm{g} / \mathrm{kg}$ and increases up to $297.3 \mu \mathrm{g} / \mathrm{kg}$ after the combustion process. In the case of wood chips, mercury content is in the range from $59.9 \mu \mathrm{g} / \mathrm{kg}$ to $295.0 \mu \mathrm{g} / \mathrm{kg}$; after the combustion process this value ranges from $177.5 \mu \mathrm{g} / \mathrm{kg}$ to $298.3 \mu \mathrm{g} / \mathrm{kg}$. For Agro-seeds, mercury content amounts to $135.6 \mu \mathrm{g} / \mathrm{kg}$ and $346.9 \mu \mathrm{g} / \mathrm{kg}$ after combustion. The mercury content in wood briquettes is $235.2 \mu \mathrm{g} / \mathrm{kg}$, while this value increases up to $339.1 \mu \mathrm{g} / \mathrm{kg}$ after the combustion process. In the case of energy crops (sunflower husk) and pellets from energy crops (e.g. sunflower), the mercury content is $280.2 \mu \mathrm{g} / \mathrm{kg}$ and $43.1 \mu \mathrm{g} / \mathrm{kg}$ (the lowest content recorded), respectively. The socalled Biomass Mix from energy crops is characterized by highly variable mercury content in the range from $36.5 \mu \mathrm{g} / \mathrm{kg}$ up to $472.4 \mu \mathrm{g} / \mathrm{kg}$.

\section{Conclusion}

Based on the research results presented in this paper, the following conclusions can be drawn:

1. Based on the measured $\mathrm{pH}$ and conductivity of biomass, presented in Table 1, it can be concluded that the samples are characterized by low $\mathrm{pH}$ (acidic, slightly acidic reaction). In contrast, $\mathrm{B} 15, \mathrm{~B} 13, \mathrm{~B} 12$, and $\mathrm{B} 5$ samples have alkaline reaction.

2. The conductivity is characterized by relatively low values; this applies particularly to the B11 sample, with electrical conductivity at $21.9 \mathrm{mS}$.

3. It should be noted that reactions between the products of decomposition of organic matter and mineral substances can be observed in aqueous solutions of biomass. It is suggested that the acidity of the solution is due to free $\mathrm{CO} 2$, mineral and organic acids.

4. The differences in $\mathrm{pH}$ and conductivity of the samples are resulting from inhomogeneities in the starting material, storage conditions and uneven course of leaching processes.

5. Analytical moisture as received is in the range from $8.94 \%$ (sample No B7 - Biomass Mix) to $4.10 \%$ (sample No 6 - Biomass from energy crops-sunflower husk).

6. The study has shown significant differences when it comes to the mercury content in individual biomass types, ranging from $36.5 \mu \mathrm{g} / \mathrm{kg}$ to $472.4 \mu \mathrm{g} / \mathrm{kg}$.

7. The highest concentrations of mercury in the amount of $472.4 \mu \mathrm{g} / \mathrm{kg}$ and the highest conductivity of $119.4 \mathrm{mS}$ were recorded for the Biomass Mix (straw, wood pellets, wood pellets from energy crops - sunflower). It is suggested that such a large accumulation of mercury may be the result of the diverse composition of biomass from various sources.

8. A one-fold, two-fold, and three-fold increase in the mercury content after the combustion of the tested samples were observed in the B1-S, B4-S, B3-S (Agro seeds, up to $346.9 \mu \mathrm{g} / \mathrm{kg}$, the highest concentration recorded) and B5 (wood briquettes, up to $339.1 \mu \mathrm{g} / \mathrm{kg}$ ) samples, respectively.

9. The only exception is the B2-S sample (wood chips), where the mercury content after the combustion process has decreased by approximately $40 \%$.

\section{References}

1. Directive 2001/77/EC of the European Parliament and of the Council of 27 September 2001 on the promotion of electricity produced from renewable energy sources in the internal electricity market (2001), publication available at http://orka.sejm.gov.pl/Drektywy.nsf/all/32001L0077/\$File/32001L0077.pdf 
2. G. Berent-Kowalska, J. Kacprowska, I. Moskal, A. Jurgaś, Central Statistical Office of Poland, Production Department, the Ministry of Energy, Energy Market Agency S.A., (2016), publication available at www.stat.gov.pl

3. Energy Mix 2050. Analysis of Scenarios for Poland. Ministry of Economy, (2011), publication available at http://poznajatom.pl/download/6f/94/17dd23f7acb9bdd550d838a98af9f753b871.pdf.

4. Poland Energy Report, Enerdata, (2012), publication available at http://www.iea.org/publications/freepublications/publication/Poland2011_web.pdf

5. Costs and environmental effectiveness of options for reducing mercury emissions to air from small-scale combustion installations, European Commission DG Environmental (2005), publication available at

http://ec.europa.eu/environment/chemicals/mercury/pdf/sci_final_report.pdf 